\title{
Aplicação de resíduo da agroindústria citrícola para a produção de hidrogênio utilizando culturas puras e mistas
}

\author{
Application of citrus agroindustry residue for \\ the production of hydrogen using pure and mixed cultures
}

\author{
Daiana Camila da Silva ${ }^{1,2}$, Luan Vieira Adames ${ }^{1,2}$ \\ Lorena Oliveira Pires ${ }^{1}$, Rodrigo Fernando Costa Marques ${ }^{1,3}$ \\ Maria Angela Tallarico Adorno ${ }^{4}$, Sandra Imaculada Maintinguer ${ }^{1,2,5}$
}

\footnotetext{
${ }^{1}$ Instituto de Química de Araraquara, IQ/UNESP. Programa de Pós-Graduação em Biotecnologia, Rua Prof. Francisco Degni ,55, Quitandinha, Araraquara, São Paulo, Brasil.

${ }^{2}$ Instituto de Pesquisa em Bioenergia, IPBEN, Laboratório Central, Rua 10, 2527, Santana, Rio Claro, São Paulo, Brasil. ${ }^{3}$ CEMPEQC - Centro de Monitoramento Pesquisa em Combustíveis Biocombustíveis e derivados, Rua Prof. Francisco Degni ,55, Quitandinha, Araraquara, São Paulo, Brasil.

${ }^{4}$ Universidade de São Paulo, USP, Laboratório de Processos Biológicos - LPB, Av. João Dagnone, 1100, Jd. Santa Angelina, São Carlos, São Paulo, Brasil.

${ }^{5}$ Universidade de Araraquara, Uniara - Programa de Pós-Graduação em Desenvolvimento Territorial e Meio Ambiente, Rua Carlos Gomes, 1338, Centro, Araraquara, São Paulo, Brasil.

e-mail: daianacsilva91@gmail.com, lorena.pires@unesp.br, sandra.i.maintinguer@unesp.br
}

\section{RESUMO}

Nos últimos anos há um interesse crescente no uso de diversos resíduos agroindustriais. No Brasil, as indústrias de alimentos acumulam uma enorme quantidade de resíduos, principalmente as de processamento de frutos cítricos. Entre as possibilidades de valorização destes resíduos, a digestão anaeróbia é uma alternativa promissora na geração de energia renovável e controle da poluição. Nesse sentido, esse estudo avaliou a digestão anaeróbia de água residuária citrícola, visando à produção biológica de hidrogênio a partir de três inóculos: (1) Clostridium Acetobutylicum ATCC 824, (2) Clostridium Beijerinckii ATCC 10132 e (3) consórcio anaeróbio obtido da água residuária citrícola. $\mathrm{O}$ experimento foi realizado em $51 \mathrm{~h}$, em triplicatas de reatores anaeróbios em batelada, alimentados com 2 fontes distintas de carbono: glicose $\left(10,7 \mathrm{~g} \mathrm{DQO} \mathrm{L}^{-1}\right)$ e água residuária citrícola (10,0 g DQO L $\left.{ }^{-1}\right)$, headspace preenchido com $\mathrm{N}_{2}(99,99 \%)$, pH inicial 7,0 e mantidos a $37^{\circ} \mathrm{C}$, sob modo estático. Nos reatores alimentados com glicose foram verificados geração de hidrogênio apenas com os inóculos 1 e 2, que foram, respectivamente, de $36,8 \mathrm{mmol} \mathrm{L}^{-1}$ e $64,1 \mathrm{mmol} \mathrm{L}^{-1}$. Nos reatores operados com água residuária citrícola foram obtidos 21,2; 15,7 e; 37,6 mmol H $\mathrm{L}^{-1}$ com os inóculos 1; 2 e 3, respectivamente. Além disso, foram verificadas gerações expressivas de etanol para todos os inóculos testados nos reatores alimentados com glicose. Na caracterização do consórcio anaeróbio citrícola foi verificado predomínio de bacilos Gram + e quantificados os gêneros de bactérias anaeróbias geradoras de $\mathrm{H}_{2}$ (UFC $\mathrm{mL}^{-}$ $\left.{ }^{1}\right)$ : Clostridium sp. $\left(3 \times 10^{5}\right)$, Bacteroides sp. $\left(4 \times 10^{5}\right)$, Lactobacillus sp. $\left(4 \times 10^{5}\right)$, Streptococcus sp. $\left(5 \times 10^{4}\right)$, e Veillonella $\mathrm{sp} .\left(3 \times 10^{5}\right)$, revelando diversidade elevada de bactérias anaeróbias produtoras de hidrogênio presentes na água residuária agroindustrial. Tais resultados ressaltam que a geração de hidrogênio pode ocorrer em vias metabólicas distintas com consequente favorecimento na geração de biocombustíveis como etanol ou butanol.

Palavras-chave: Águas Residuárias. Citricultura. Fermentação. Clostridium

\section{ABSTRACT}

In recent years there has been a growing interest in the use of various agro-industrial wastes. In Brazil, the food industries accumulate an enormous amount of waste, especially those that process citrus fruits. Among the possibilities for valuing these residues, anaerobic digestion is a promising alternative in the generation of renewable energy and pollution control. In this sense, this study evaluated the anaerobic digestion of citrus wastewater, aiming at the biological production of hydrogen from three inocula: (1) Clostridium Acetobutyli- 
cum ATCC 824, (2) Clostridium Beijerinckii ATCC 10132 and (3) anaerobic consortium obtained from citrus wastewater. The experiment was carried out in $51 \mathrm{~h}$, in triplicates of anaerobic batch reactors, fed with 2 different carbon sources: glucose $\left(10.7 \mathrm{~g} \mathrm{COD} \mathrm{L}^{-1}\right)$ and citrus wastewater $\left(10.0 \mathrm{~g} \mathrm{COD} \mathrm{L}^{-1}\right)$, headspace filled with $\mathrm{N}_{2}(99.99 \%)$, initial pH 7.0 and maintained at $37^{\circ} \mathrm{C}$, under static mode. In the reactors fed with glucose, hydrogen generation was verified only with the inocula 1 and 2, which were, respectively, $36.8 \mathrm{mmol} \mathrm{L}^{-1}$ and $64.1 \mathrm{mmol} \mathrm{L}^{-1}$. In the reactors operated with citrus wastewater, were obtained 21.2; $15.7 \mathrm{e} ; 37.6 \mathrm{mmol} \mathrm{H}_{2} \mathrm{~L}^{-1}$ with inocula 1; 2 and 3, respectively. In addition, expressive generations of ethanol were verified for all inocula tested in the reactors fed with glucose. In the characterization of the citrus anaerobic consortium, a predominance of Gram + bacilli was verified and the genera of anaerobic $\mathrm{H}_{2}$-generating bacteria $\left(\mathrm{UFC} \mathrm{mL}^{-1}\right)$ were quantified: Clostridium sp. $\left(3 \times 10^{5}\right)$, Bacteroides sp. $\left(4 \times 10^{5}\right)$, Lactobacillus sp. $\left(4 \times 10^{5}\right)$, Streptococcus $\mathrm{sp}$. $\left(5 \times 10^{4}\right)$, and Veillonella sp. $\left(3 \times 10^{5}\right)$, revealing a high diversity of anaerobic hydrogen-producing bacteria present in agro-industrial wastewater. Such results emphasize that the generation of hydrogen can occur in different metabolic pathways with consequent favor in the generation of biofuels such as ethanol or butanol.

Keywords: Wastewater. Citrus. Fermentation. Clostridium.

\section{INTRODUÇÃO}

Preocupação ambiental global e oscilações incessantes no preço do petróleo bruto levaram a estratégias para produção de biocombustíveis derivados de recursos renováveis, principalmente os advindos da fermentação microbiana, a fim de reduzir impactos ambientais associados à emissão de gases de efeito estufa $[1,2]$.

Os biocombustíveis representam uma alternativa ecológica sustentável, econômica e promissora para os combustíveis fósseis. O hidrogênio é considerado um combustível de energia limpa com densidade de energia de $122 \mathrm{KJ} \mathrm{g}^{-1}$, que é três vezes mais elevado que os combustíveis de hidrocarbonetos [3].

As frutas cítricas estão entre as culturas mais cultivadas no mundo e seus sucos são os mais amplamente consumidos [4]. A laranja está entre as frutas mais produzidas e consumidas no mundo, sendo o Brasil o maior produtor mundial da cultura citrícola, com uma produção de laranja de 1.202 .792 toneladas na safra 2019/2020. O Estado de São Paulo representa 70,6\% da produção citrícola no Brasil. O estado de São Paulo representa 70,6\% da produção citrícola no Brasil [5]. Em média, 34\% da produção é destinada à produção de suco, entretanto, em países como o Brasil e Estados Unidos, esta percentagem chega a 96\%, o que gera grande quantidade de resíduos. Uma desvantagem decorrente desse resíduo é que pode gerar águas residuárias altamente poluidoras, em termos de valores de demanda química e demanda bioquímica de oxigênio (DQO e DBO), tornando-se um risco significativo para corpos d'água, além da produção de gases de efeito estufa [6], sendo necessário tratamento adicional desse efluente ou sua disposição em aterros sanitários, o que é oneroso para a indústria [4].

Entre os diferentes resíduos agroflorestais gerados durante a colheita ou processamento industrial, os resíduos de frutas cítricas são fonte de energia renovável abundante, barata e prontamente disponível. Além disso, tais resíduos não têm aplicações comerciais, portanto, tornam-se desperdício inevitável da agroindústria, envolvendo preocupações ambientais severas [1].

Processos bioquímicos (digestão anaeróbia e fermentação) químicos e termoquímicos (pirólise, gaseificação e/ou combustão) têm sido propostos como vias ambientalmente corretas para a valorização desse resíduo. A sua utilização como fonte de carbono no processo de digestão anaeróbia é uma alternativa eficiente de tratamento com remoção de matéria orgânica e eliminação ou redução de compostos tóxicos, minimizando a poluição ambiental e proporcionando a recuperação de energia.

A fermentação de fontes de carbono residuais para a produção de hidrogênio e coprodutos utilizando consórcio de bactérias anaeróbias se torna um processo vantajoso no ponto de vista econômico, quando comparado a utilização de culturas puras devido a dificuldade de manter o processo em condições esterilizadas e também pelo fato de existir meios de cultivo com carboidratos específicos para as cepas puras. Todavia, são poucas as pesquisas envolvendo a obtenção de hidrogênio e coprodutos a partir de resíduos de citricultura.

Nesse sentido, o objetivo dessa pesquisa foi avaliar água residuária citrícola na produção biológica de hidrogênio, em reatores em batelada com culturas puras e mistas obtidas advindas da própria água residuária citrícola.

\section{MATERIAL E MÉTODOS}

\subsection{Substrato}

Fontes de carbono utilizadas como substrato foram: glicose P.A. $\left(10,7 \mathrm{~g}\right.$ DQO L $\left.\mathrm{L}^{-1}\right)$ e água residuária citrícola (pH 11,12; 22,4 g DQO L ${ }^{-1}, 6,22 \mathrm{~g} g l i c o s e ~^{-1} ; 8,2 \mathrm{~g}$ sólidos totais $\mathrm{L}^{-1} ; \mathrm{e} 4,5 \mathrm{~g}$ sólidos voláteis $\mathrm{L}^{-1}$ ), proveniente do processamento da laranja, cedida pela indústria de cítricos localizada em Araras - SP (22 $24^{\prime} 39^{\prime \prime}$ S 
$47^{\circ} 33^{\prime} 39^{\prime \prime} \mathrm{W}$ ) e mantida $-20^{\circ} \mathrm{C}$ até sua utilização. Foi realizada a remoção de partículas grosseiras, para remover sólidos suspensos insolúveis e sedimentados, previamente à sua utilização, descritos a seguir.

\subsection{Fontes de inóculo e condições de cultivo}

Os inóculos utilizados foram: (1) Clostridium acetobutylicum ATCC 824, (2) Clostridium beijerinkii ATCC 10132 e (3) consórcio anaeróbio obtido a partir do resíduo citrícola.

As culturas puras Clostridium acetobutylicum e Clostridium beijerinkii (inóculos 1 e 2) foram reativadas em triplicatas de reatores anaeróbios em batelada $(500 \mathrm{~mL})$, headspace $(200 \mathrm{~mL})$ preenchidos com $\mathrm{N}_{2}$ (99,99\%) em meio de cultivo PYG (Peptone, Yeast Extract, Glucose) (300 mL) contendo $\left(\mathrm{g} \mathrm{L}^{-1}\right)$ : glicose (10); peptona $(5,0)$, extrato de carne $(5,0)$ e extrato de levedura $(5,0)$, separadamente. Os reatores foram mantidos a $37{ }^{\circ} \mathrm{C}$, $\mathrm{pH}$ inicial 7,0 , durante 72 horas. A seguir, foram realizados repiques nas mesmas condições descritas anteriormente, com o objetivo de aumentar a biomassa para ensaios de geração de hidrogênio.

O consórcio anaeróbio citrícola [inóculo (3)] foi obtido através da coleta de alíquota de $1 \mathrm{~mL}$ do resíduo citrícola e inserido em reatores anaeróbios em batelada $(100 \mathrm{~mL})$, contendo meio de cultivo PYG $(50 \mathrm{~mL})$, headspeace $(50 \mathrm{~mL})$ preenchido com $\mathrm{N}_{2}(99,99 \%)$, $\mathrm{pH}$ inicial 7,0 e mantido a $37^{\circ} \mathrm{C}$, em modo estático por 72 horas. Posteriormente, foi realizado o enriquecimento celular pela técnica de diluições seriais $\left(10^{-1}\right.$ a $\left.10^{-5}\right)$, repetidas vezes, nas mesmas condições descritas anteriormente, por 120 horas.

Os inóculos (1), (2) e (3) foram reativados em triplicatas de reatores anaeróbios em batelada, nas mesmas condições descritas anteriormente, por 72 horas, com o objetivo de favorecer o crescimento das bactérias anaeróbias presentes na amostra. Esse processo foi realizado repetidas vezes até o volume de $500 \mathrm{~mL}$ dos reatores $(250 \mathrm{~mL}$ de meio de cultivo), separadamente para cada inóculo.

A seguir, as amostras foram centrifugadas e $20 \%$ (v/v) dos sedimentados (inóculos 1, 2 e 3) foram transferidos para reatores anaeróbios em batelada, contendo separadamente glicose e resíduo citrícola como fonte de carbono, descrito a seguir.

\subsection{Operação dos reatores anaeróbios em batelada}

Os ensaios de geração de $\mathrm{H}_{2}$ foram realizados em triplicatas de reatores anaeróbios em batelada $(500 \mathrm{~mL})$ que consistiam de $250 \mathrm{~mL}$ de meio reacional contendo $\left(\mathrm{g} \mathrm{L}^{-1}\right)$ peptona $(5,0)$, extrato de carne $(5,0)$ e extrato de levedura $(5,0)$, com headspace $(500 \mathrm{~mL})$ preenchido com $\mathrm{N}_{2}(99,99 \%)$, para manter a anaerobiose, em $\mathrm{pH}$ inicial 7,0, mantidos em modo estático, a $37^{\circ} \mathrm{C}$ por 51 horas, com os inóculos (1), (2) e (3) em $20 \%$ (v/v). As fontes de carbono adicionadas foram glicose $\left(10,7 \mathrm{~g}^{\mathrm{DQO} \mathrm{L}} \mathrm{L}^{-1}\right)$ para o ensaio 1 e água residuária citrícola $(10$ g DQO L ${ }^{-1}$ ) para o ensaio 2, separadamente.

\subsection{Análises físico-químicas e cromatográficas}

Os consumos de carboidratos foram realizados por espectrofotometria a $490 \mathrm{~nm}$ (OD490) [7].

O crescimento celular foi monitorado por espectrofotometria a $600 \mathrm{~nm}(\mathrm{OD} 600)$ e a Demanda Química de Oxigênio (DQO) a $620 \mathrm{~nm}(\mathrm{OD} 620)$ [8].

$\mathrm{O}$ pH foi ajustado com adições de $\mathrm{NaOH}(1 \mathrm{M})$ ou $\mathrm{HCl}(1 \mathrm{M})$ e monitorado no final da operação dos reatores, [8]. [9].

A quantificação do gás hidrogênio gerado foi mensurada através do deslocamento de volume, adaptado

Análises esporádicas da composição do biogás foram realizadas em parceria com os laboratórios de processos biológicos LPB na USP - EESC - S. Carlos - SP, em cromatrógrafo Shimadzu, modelo GC 2010, usando um detector de condutividade térmica e argônio como gás de arraste. As temperaturas do injetor, detector e coluna foram mantidas a $30^{\circ} \mathrm{C}, 200^{\circ} \mathrm{C}$ e $230{ }^{\circ} \mathrm{C}$, respectivamente [10].

A geração de compostos orgânicos gerados na fase liquida, como ácidos graxos voláteis e álcoois, foi quantificada em parceria com CEMPEQC (Centro de Monitoramento Pesquisa em combustíveis Biocombustíveis Petróleo e Derivados) - IQ - Unesp - Araraquara - SP por cromatografia em fase gasosa, utilizando um GC 2010 (Shimatzu ${ }^{\circledR}$ ), configurado para amostragem de líquidos e headspace, uma temperatura programável do detector PTV e FID a $250^{\circ} \mathrm{C}$. A temperatura do forno foi programada inicialmente a $45^{\circ} \mathrm{C}$ por 1 min, seguida por uma rampa de aquecimento de $50^{\circ} \mathrm{C} \mathrm{min}^{-1}$ até uma temperatura final de $250^{\circ} \mathrm{C}$, mantida por $3 \mathrm{~min}$. A coluna analítica utilizada foi o RTX-1 $(30 \mathrm{~m} \times 0,32 \mathrm{~mm} \times 3,0 \mu \mathrm{m})$. Hélio foi utilizado como gás portador $51,6 \mathrm{~cm} \mathrm{~s}^{-1}\left(1 \mathrm{~mL} \mathrm{~min}^{-1}\right)[11]$. 


\subsection{Ajuste dos dados experimentais}

A produção de hidrogênio foi ajustada para valores médios de triplicatas em reatores em batelada utilizando o software Statistic ® (versão 8.0), de acordo com a Equação (1). A taxa máxima de produção de hidrogênio foi obtida através do ajuste sigmoidal não linear da função Gompertz modificada [12].

$\mathrm{H}=\mathrm{P} \times \exp \{-\exp [((\mathrm{Rm} . e) / \mathrm{P})(\lambda-\mathrm{t})+1]\}$ onde:

$\mathrm{H}$ representa o hidrogênio acumulativo (mmol), $\mathrm{P}$ é o potencial de produção de hidrogênio (mmol $\mathrm{L}^{-1}$ ), $\mathrm{Rm}$ é a taxa máxima de produção de hidrogênio $\left(\mathrm{mmol} \mathrm{L}^{-1} \mathrm{~h}\right), \lambda$ é o tempo de inicio da geração de $\mathrm{H}_{2}(\mathrm{~h}), e$ é igual a 2,718281828 e t é o tempo de incubação (h).

\subsection{Análises microbiológicas}

Exames microscópicos foram realizados através de luz comum e contraste de fase, em microscópio Olimpus para observação das morfologias predominantes, durante a operação dos reatores anaeróbios com os inóculos testados, em técnica de coloração de Gram para diferenciação de microrganismos Gram+e Gram-.

Quantificações de bactérias anaeróbias geradoras de $\mathrm{H}_{2}$ foram realizadas em meio seletivo por técnica de pour plate (em Unidades Formadoras de Colônias por $\mathrm{mL}$ ) para os gêneros: Clostridium sp., Bacteroides sp., Lactobacillus sp., Enterobacter sp., Veillonella sp. e Streptococcus sp. [13]. As placas foram incubadas e mantidas a $37^{\circ} \mathrm{C}$, em anaerobiose, durante 6 dias ou até o surgimento das colônias. Para assegurar a confiabilidade dos resultados, todas as diluições foram realizadas em triplicata. As contagens foram realizadas manualmente.

\section{RESULTADOS E DISCUSSÃO}

No ensaio 1 foi verificado crescimento da biomassa em glicose e tal comportamento foi similar para os 3 inóculos testados (Figura 1), com ocorrência de fase lag até duas horas de operação e estabilização em aproximadamente $30 \mathrm{~h}$.

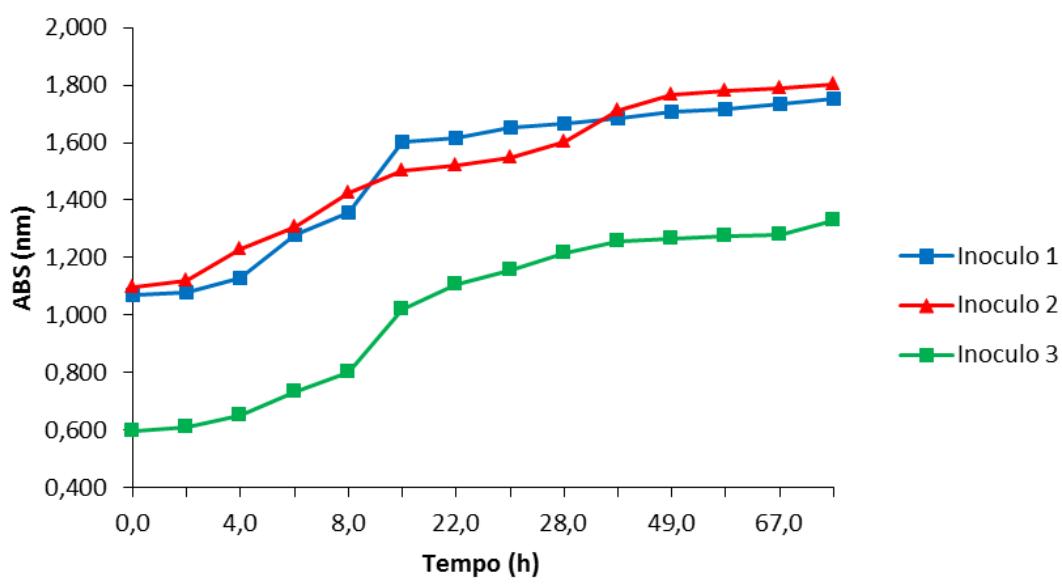

Figura 1: Crescimento dos inóculos (1) Cl. acetobutylicum; (2) Cl. beijerinckii e (3) consórcio anaeróbio citrícola em glicose.

Com a ocorrência da fermentação foi verificado decaimento do pH em 4,5; confirmando a dissociação de ácidos orgânicos, com geração de outros produtos por microrganismos [14] ocasionado pelos consumos de glicose de 50\%, 64\% e 68\%, para os inóculos (1), (2) e (3), respectivamente. Além disso, foi verificada geração de ácidos orgânicos como ácido acético e a formação de butírico que geralmente pode ocorrer em $\mathrm{pH}$ próximo a 5,0 [15]. Os resultados de DQO inicial e final não tiveram alterações significativas e variaram de: 28,7 a 23,0 $\mathrm{g} \mathrm{L}^{-1}$ (inóculo1) e; 26,3 a 25,03 $\mathrm{g} \mathrm{L}^{-1}$ (inóculos 2 e 3), corroborando com a permanência de ácidos e álcoois na fase líquida dos reatores, conforme descrito a seguir.

Os produtos intermediários gerados nos reatores anaeróbios alimentados com glicose, em concentrações mais elevadas foram $\left(\mathrm{mg} \mathrm{L}^{-1}\right)$ : ácido acético $(246,5)$; butanol $(306,9)$ e etanol $(1571,8)$, respectivamente para os reatores operados com os inóculos 1, 2 e 3 (Figura 2). 


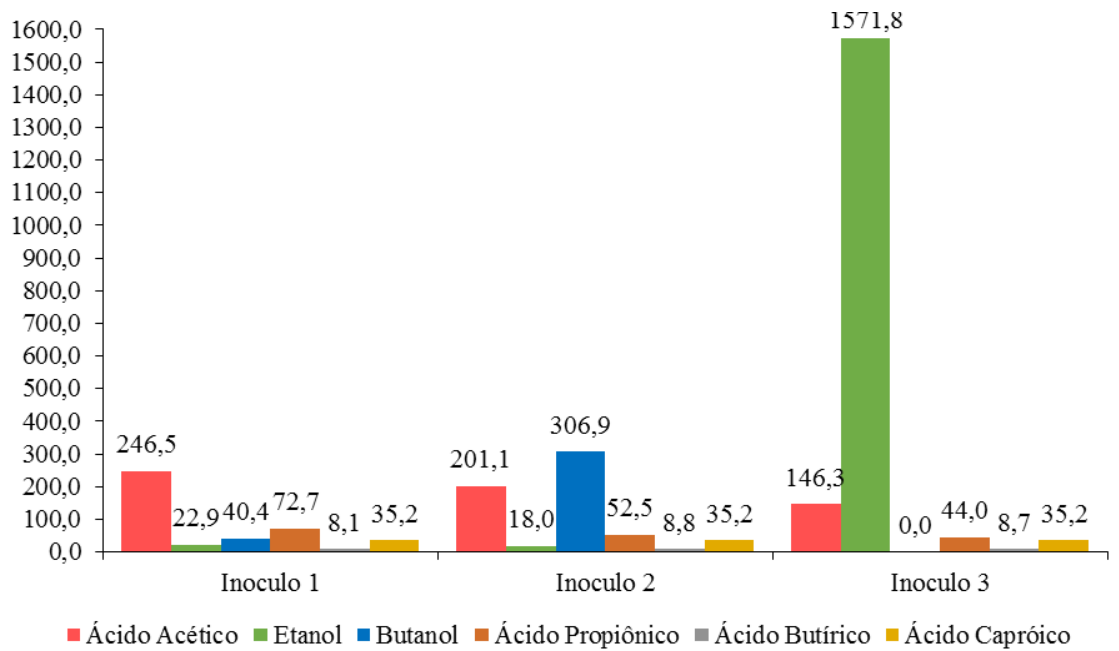

Figura 2: Produtos intermediários gerados nos reatores anaeróbios alimentados com glicose, para Inóculos 1, 2 e 3

A fermentação da glicose por culturas puras e mistas pode gerar diferentes tipos de ácidos graxos voláteis e álcoois durante a etapa de acidogênese por várias vias metabólicas [14, 16]. Com 19 horas de operação ocorreu o acúmulo de ácido butírico de 22,0 e 12,8 $\mathrm{mg} \mathrm{L}^{-1}$ nos reatores operados com inóculos 1 e 2 , respectivamente e após esse período, a concentração de ácido butírico diminuiu para até $8,1 \mathrm{mg} \mathrm{L}^{-1}$ com a formação de butanol $\left(40,4\right.$ e $\left.306,9 \mathrm{mg} \mathrm{L}^{-1}\right)$ e etanol $\left(22,9\right.$ e $\left.18,2 \mathrm{mg} \mathrm{L}^{-1}\right)$, respectivamente. Contrariamente, nos reatores operados com inóculo 3 foram verificadas as gerações mais elevadas de etanol $\left(1571,8 \mathrm{mg} \mathrm{L}^{-1}\right)$ em 67 horas de operação. De acordo com AL-SHORGANI, et al. [17] a produção de butanol na fase solventogênica tem início com a redução nas quantidades do ácido butírico, conforme verificado no presente estudo para os inóculos 1 e 2, que são culturas de Clostridium, provavelmente devido ao fato de serem microrganismos específicos para a produção deste álcool [18]. Entretanto, nos reatores operados com o inóculo 3 foi verificado alteração da rota metabólica para a geração de etanol (1571,8 $\mathrm{mg} \mathrm{L}^{-1}$ ) (Figura 2). Esse dado justificou a ausência da produção de $\mathrm{H}_{2}$, onde a rota metabólica foi favorecida para a geração deste álcool [17].

A rota metabólica da glicose em processos fermentativos pode ocorrer com geração de $\mathrm{H}_{2}$ na fase gasosa e produtos intermediários como etanol, butanol, ácidos acético, butírico, capróico e propiônico, que podem ser produzidos no metabolismo oxidativo [19] na fase líquida, conforme observado no presente estudo. Isto sugeriu que houve uma transformação da glicose a outros compostos orgânicos na fase liquida, causando a manutenção da DQO ao longo dos ensaios. Além disso, tal ocorrência foi confirmada com a ausência de metano no headspace dos reatores anaeróbios em batelada. Certamente, a ausência de microrganismos consumidores desses metabólitos como arquéias metanogênicas foi a principal causa da manutenção da DQO no meio líquido.

Não foi verificada geração de hidrogênio com o inóculo (3) para essa condição. Entretanto, os ensaios com as culturas puras (inóculos 1 e 2), foram verificadas gerações de $36,8 \mathrm{mmol} \mathrm{H}_{2} \mathrm{~L}^{-1}$ e $64,1 \mathrm{mmol} \mathrm{H}_{2} \mathrm{~L}^{-1}$, respectivamente. Pelo ajuste sigmoidal da função de Gompertz modificada (Figura 3), os parâmetros estimados de fase inicial de geração de $\mathrm{H}_{2}(\mathrm{~L})$, produção máxima $(\mathrm{P})$ e taxa de produção $(\mathrm{Rm})$, foram respectivamente para os inóculos 1 e 2: $\mathrm{L}=17,13$ e 15,85 horas; $\mathrm{P}=36,8$ e $64,1 \mathrm{mmol} \mathrm{H}_{2} \mathrm{~L}^{-1}$; e $\mathrm{Rm}=9,12$ e 1,69 mmol $\mathrm{H}_{2} \mathrm{~L}^{-1} \mathrm{~h}^{-1}$. Os coeficientes de determinação $\left(\mathrm{R}^{2}\right)$, obtidos pelo tratamento estatístico [(1) 1,0 e (2) 0,998], reforçaram que o modelo adotado representou os dados obtidos experimentalmente, nos reatores anaeróbios em batelada alimentados com glicose. Mais uma vez a rota metabólica de geração de hidrogênio foi favorecida nos reatores operados com culturas puras de Clostridium (inóculos 1 e 2) que são espécies produtoras de $\mathrm{H}_{2}$ a partir de açúcares [20], principalmente glicose [10] e inativada para os reatores operados com o consórcio citrícola, com a geração expressiva de etanol. 


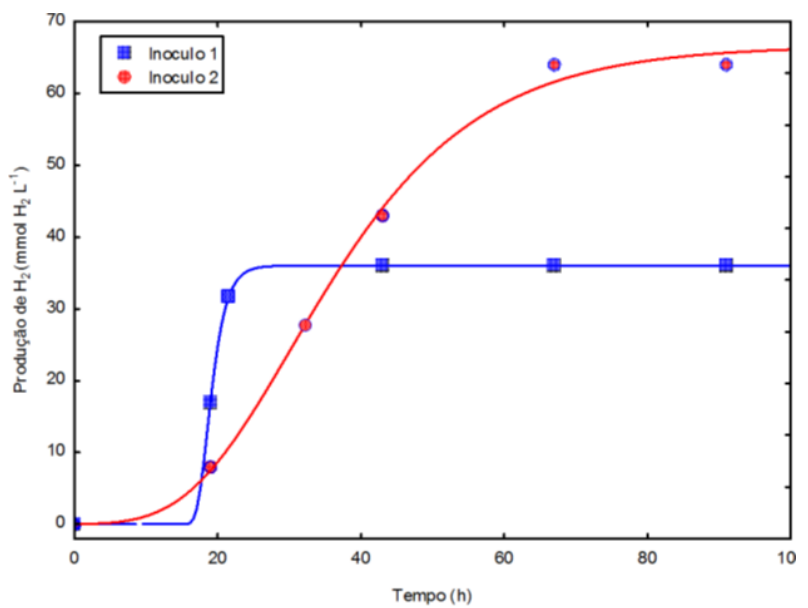

Figura 3: Ajuste sigmoidal da função de Gompertz modificada na geração de hidrogênio para os inóculos 1 em reatores anaeróbios alimentados com glicose.

No ensaio 2, com água residuária citrícola como fonte de carbono, os inóculos (1), (2) apresentaram crescimento da biomassa microbiana reduzida (Figura 4). Tal fato provavelmente foi atribuído pela quantidade inicial de biomassa adicionada. Contrariamente, para o inóculo 3 foi verificado crescimento expressivo. Os ensaios com glicose (Ensaio 1) e com água residuária citrícola (Ensaio 2) ocorreram respectivamente em $73 \mathrm{~h}$ e 51 h. Além disso, o consórcio anaeróbio proveniente da água residuária citrícola estava adaptado a essa fonte de carbono, o que explicou a diferença verificada entre os inóculos testados.

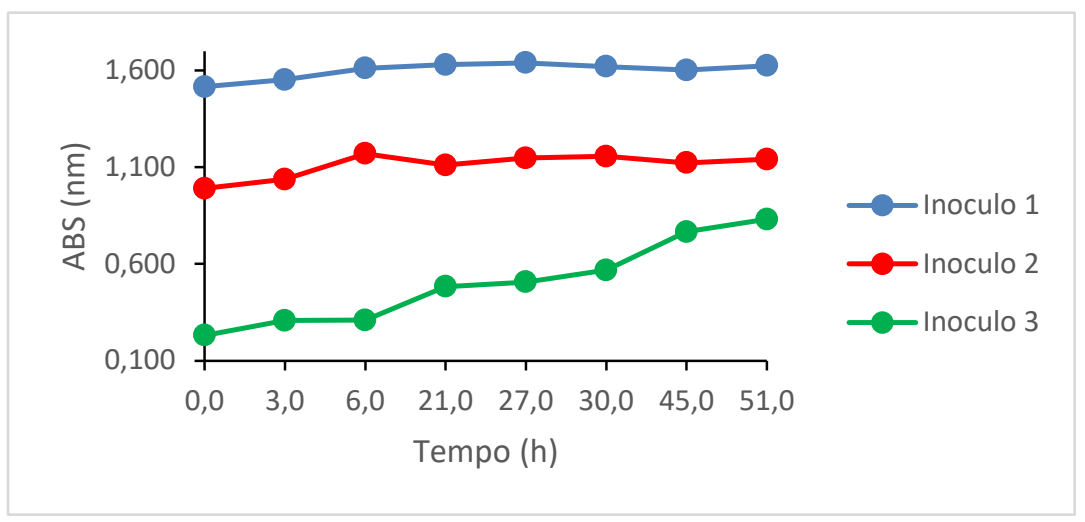

Figura 4: Crescimento dos inóculos (1) Cl. acetobutylicum; (2) Cl. beijerinckii e (3) consórcio anaeróbio citrícola em água residuária citrícola.

Em todos os reatores alimentados com água residuária citrícola foi observado comportamento diretamente proporcional entre o consumo de carboidratos e a produção acumulada de gás hidrogênio. Os consumos de carboidratos foram de, 68\%, 43\% e 56\% respectivamente, com os inóculos (1), (2) e (3). Os valores de DQO no início e final da operação não se alteraram significativamente e foram de $16,4 \mathrm{~g} \mathrm{~L}^{-1}$ a $14,7 \mathrm{~g} \mathrm{~L}^{-1}$ nos ensaios com as culturas puras (inóculos 1 e 2) e 14,0 a $11,4 \mathrm{~g} \mathrm{~L}^{-1}$ no ensaio com o consórcio anaeróbio citrícola (inóculo 3), corroborando com o processo fermentativo e consequente geração de ácidos e álcoois observados e descritos a seguir.

Os reatores anaeróbios operados com o inóculo (3) apresentaram valores mais elevados de geração de hidrogênio $\left(37,6 \mathrm{mmol} \mathrm{H}_{2} \mathrm{~L}^{-1}\right)$ do que os obtidos nos reatores com as culturas puras que são conhecidas como produtoras de hidrogênio [21,2 $\mathrm{mmol} \mathrm{H}_{2} \mathrm{~L}^{-1}$ (inóculo 1) e $15,7 \mathrm{mmol} \mathrm{H}_{2} \mathrm{~L}^{-1}$ (inóculo 2)]. SOARES et al.[21] avaliaram a produção de hidrogênio a partir de bagaço de cana em pré-tratado hidrotermicamente, em reatores anaeróbios em batelada $(1 \mathrm{~L})$, com inóculo $(10 \% \mathrm{v} / \mathrm{v})$ proveniente de solo e resíduo de compostagem e substrato, em $\mathrm{pH} 6,0$, a $37^{\circ} \mathrm{C}$, por 400 horas e obtiveram $1,50 \mathrm{mmol} \mathrm{H}_{2} \mathrm{~L}^{-1}$ utilizando $2,77 \mathrm{~g} \mathrm{~L}^{-1}$ de extrato de levedura e $5,84 \mathrm{~g} \mathrm{~L}^{-1}$ de bagaço de cana pré-tratado. Tais resultados foram inferiores aos obtidos no presente estudo, para os reatores alimentados com água residuária citrícola gerando $\mathrm{H}_{2}(21,2 ; 15,7$ e 37,6 mmol $\mathrm{H}_{2} \mathrm{~L}^{-1}$ respectivamente, para os ensaios com os inóculos 1,2 e 3). 
Pelo ajuste sigmoidal da função de Gompertz modificada (Figura 5), os parâmetros estimados de fase inicial de geração de $\mathrm{H}_{2}(\mathrm{~L})$, produção máxima $(\mathrm{P})$ e taxa de produção $(\mathrm{Rm})$, foram respectivamente para os inóculos 1, 2 e 3: $\mathrm{L}=7,6 ; 10,8$ e 23,3 horas; $\mathrm{P}=; 21,0 ; 16,0$ e $37,8 \mathrm{mmol} \mathrm{H}_{2} \mathrm{~L}^{-1}$; e $\mathrm{Rm}=0,9 ; 3,1$ e 4,9 mmol $\mathrm{H}_{2} \mathrm{~L}^{-1} \mathrm{~h}^{-1}$. Os coeficientes de determinação $\left(\mathrm{R}^{2}\right)$, obtidos pelo tratamento estatístico [(1) 1,$0 ;(2) 1,0$ e (3) 0,997 ; ], reforçaram que o modelo adotado representou os dados obtidos experimentalmente nos reatores anaeróbios em batelada, alimentados com água residuária citrícola.

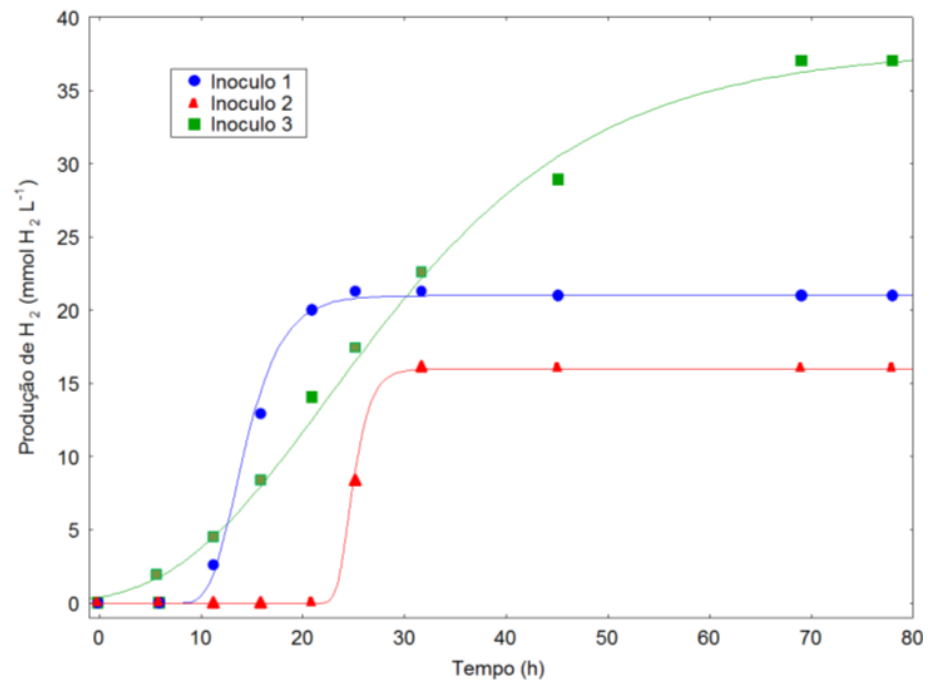

Figura 5: Ajuste sigmoidal da função de Gompertz modificada da geração de hidrogênio para os inóculos $1(\bullet), 2(\boldsymbol{\Delta})$ e $3(\boldsymbol{\square})$ em reatores anaeróbios alimentados com água residuária citrícola.

O pH próximo a 11,12 da água residuária citrícola foi um dos fatores que provavelmente inibiu arqueias metanogênicas nos ensaios realizados, uma vez que tais microrganismos sobrevivem somente em faixas de $\mathrm{pH}$ próximos a 7,0.

Os ácidos orgânicos gerados em concentrações mais elevadas foram acético e propiônico, para os inóculos 1, 2 e 3. O ácido butírico se manteve presente em concentrações mais reduzidas, variando de 8,0 a 9,9 mg $\mathrm{L}^{-1}$ no decorrer dos ensaios. Com 21 horas de operação foi verificada produção de etanol para todos os inóculos. As concentrações máximas de etanol foram de 27,1 e $28,7 \mathrm{mg} \mathrm{L}^{-1}$ em 30 horas de operação, nos reatores operados com as culturas puras (inóculos 1 e 2, respectivamente). Entretanto, a maior concentração de etanol foi de $82,8 \mathrm{mg} \mathrm{L}^{-1}$ em 45 horas de operação nos reatores com o consórcio citrícola (inóculo 3). Tais resultados confirmaram o favorecimento da fermentação etanólica nos reatores inoculados com o consórcio anaeróbio citrícola. (Figura 6).

No presente estudo foram observadas concentrações elevadas de ácido acético que, provavelmente foram gerados por bactérias anaeróbias que produziram $\mathrm{H}_{2}$. Ácidos acético e butírico são produzidos na primeira fase da fermentação, com o consumo de glicose e consequente crescimento celular e produção de hidrogênio, conforme observado no presente estudo. Entretanto, quando a célula entra na fase estacionária de crescimento, o seu metabolismo pode ser alterado para a produção de solventes. Concentrações mais elevadas de ácido acético e butírico favorecem a produção de gás hidrogênio [22]. 


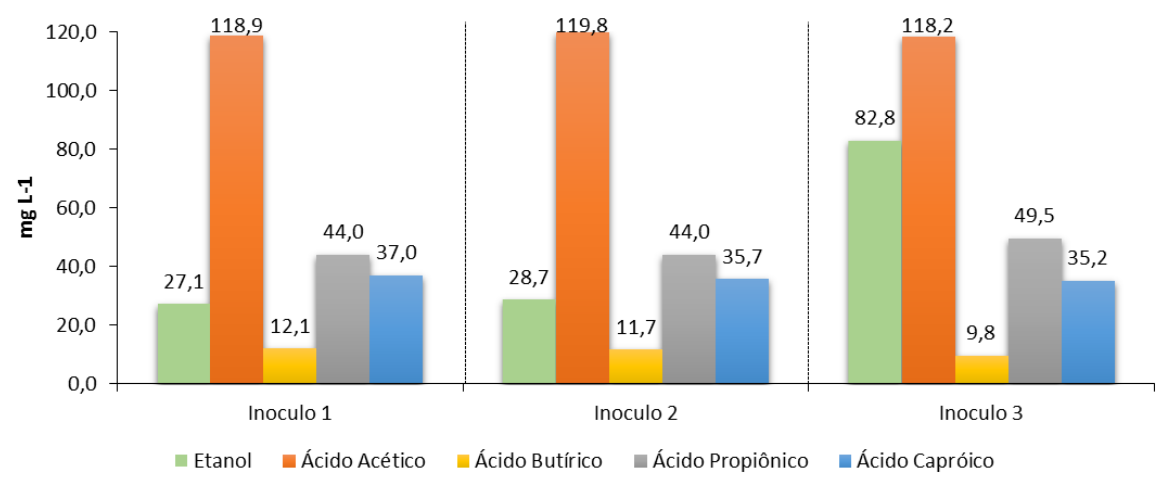

Figura 6: Variação temporal dos produtos intermediários gerados nos reatores anaeróbios alimentados com resíduo citrícola, para Inóculo 1, 2 e 3.

A eficiência da produção de ácidos graxos voláteis pode estar diretamente relacionada a presença do gênero Clostridium na microbiota dos reatores [15]. Este dado foi verificado na análise de quantificação de bactérias anaeróbias por pour plate nos ensaios realizados com as culturas puras (inóculos 1 e 2) e com o consórcio citrícola (inóculo 3), conforme descrito a seguir. Para as culturas puras foram verificadas Unidades Formadoras de Colônias (UFC $\mathrm{mL}^{-1}$ ) do gênero Clostridium de: $2 \times 10^{6}$ (inóculo 1) e 1,4x10 (inóculo 2). Para o inóculo 3 foram verificadas (UFC $\left.\mathrm{mL}^{-1}\right)$ Clostridium sp. $\left(3 \times 10^{5}\right)$, Bacteroides sp. $\left(4 \times 10^{5}\right)$, Lactobacillus sp. $\left(4 \times 10^{5}\right)$, Streptococcus sp. $\left(5 \times 10^{4}\right)$ e Veillonella sp. $\left(3 \times 10^{5}\right)$ (Figura 7). ETCHEBEHERE et al. [23] e VALDEZ-VAZQUEZ e POGGI-VARALDO [24] apontaram que o Gênero Clostridium sp. possui potencial elevado de produção de gás hidrogênio e solventes como etanol e butanol, além de serem microrganismos eficientes na degradação de carboidratos simples e complexos, resistentes a substâncias tóxicas, escassez de nutrientes e valores de pH abaixo de 6 [25 - 28]. PACHIEGA et al. [20] obteve geração de hidrogênio em reatores anaeróbios alimentados separadamente com glicose, frutose, sacarose e xilose com consórcio de bactérias anaeróbias de lodo granular, tratando resíduos de cervejaria, identificado nos gêneros Clostriduim sp., Veillonella sp., Streptococcus sp. e inferiu que tais microrganismos estavam envolvidos nos processos fermentativos de geração de $\mathrm{H}_{2}$, como no presente estudo. ROSA et al. [29] obteve geração de $\mathrm{H}_{2}$ em reator de leito fluidizado inoculados com lodo granular de suinocultura e avicultura com microrganismos pertencentes aos gêneros Veillonella e Lactobacilus e alimentados com água residuária de soro de queijo $\left(5 \mathrm{~g} \mathrm{~L}^{-1}\right)$, como verificado no presente estudo. Além disso, bactérias do gênero Bacteroides sp. verificadas no presente estudo, são reconhecidas como geradores de reduzidas quantidades de $\mathrm{H}_{2}$, quando comparadas às do gênero Clostridium [30].

Para o meio seletivo do gênero Enterobacter sp. não foi verificado crescimento de colônias. Tais resultados corroboraram com a microscopia que revelou a predominância de bacilos Gram + (Figura 8), morfologia característica de microrganismos com potencial de produção de $\mathrm{H}_{2}$ [23], como os do Gênero Clostridium. A ausência do gênero Enterobacter no consórcio anaeróbio citrícola provavelmente ocorreu pelas condições operacionais de anaerobiose impostas que inibiram o desenvolvimento de tais bactérias anaeróbias facultativas $[31,32]$.

A produção de $\mathrm{H}_{2}$ foi mais elevada com água residuária citrícola (Ensaio 2) nos reatores com o consórcio anaeróbio citrícola (inóculo 3) do que com as culturas puras (inóculos 1 e 2). Além disso, no ensaio 2 com reatores alimentados com água residuária citrícola foram obtidas gerações de $\mathrm{H}_{2}$ mais reduzidas, em comparação ao ensaio 1, com reatores anaeróbios alimentados com glicose como fonte de carbono. Isso provavelmente ocorreu em função da presença de possíveis compostos inibitórios presentes na água residuária citrícola. 


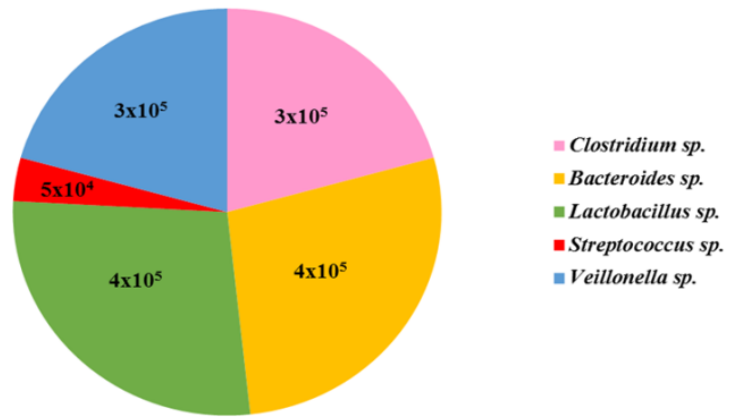

Figura 7: Quantificação de bactérias anaeróbias por técnica de pour plate do consórcio anaeróbio citrícola.

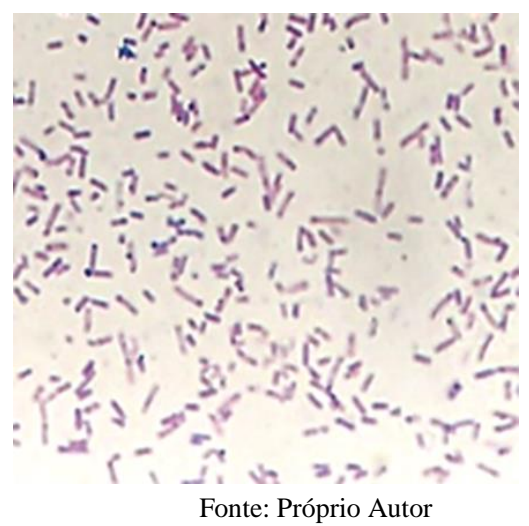

Figura 8: Caracterização morfológica do consórcio anaeróbio citrícola: predomínio de Bacilos Gram+. Ampliação de $1000 \mathrm{X}$.

\section{CONCLUSÕES}

Os testes realizados com água residuária citrícola como fonte de carbono apresentaram potencial na produção de hidrogênio e álcoois, principalmente etanol e butanol.

O consórcio anaeróbio advindo do resíduo citrícola apresentou resultados promissores na geração de $\mathrm{H}_{2}$, quando comparado com as culturas puras de Clostridium que são reconhecidas em produção de hidrogênio.

A presença dos ácidos orgânicos nos ensaios realizados em glicose e em água residuária citrícola indicou a ocorrência da fase acidogênica e solventogênese na rota metabólica das bactérias presentes, durante a operação dos reatores, inoculados com culturas puras e com o consórcio anaeróbio citrícola.

A geração de álcoois verificada nos ensaios realizados e confirmou a alteração nas rotas metabólicas, com consequentes gerações de $\mathrm{H}_{2}$, etanol e butanol que são biocombustíveis sustentáveis.

$\mathrm{Na}$ quantificação de colônias anaeróbias foi observada a diversidade de bactérias anaeróbias produtoras de hidrogênio principalmente as pertencentes aos gêneros Bacteroides, Clostridium, Veillonella e Streptococcus presente na água residuária citrícola.

A água residuária citrícola pode ser aplicada na geração de energia renovável por processos anaeróbios.

\section{AGRADECIMENTOS}

A Capes pela concessão da bolsa de doutorado.

À FAPESP (Proc. 2017/16795-3 e Proc. 2017/22401-8), ao CNPq (Projeto Universal 407298 / 2018-5) pelo suporte financeiro na manutenção das análises laboratoriais.

À USP - EESC - LPB (Laboratório de Processos Biológicos) e à UNESP - IQ - CEMPEQC (Centro de Monitoramento e Pesquisa da Qualidade de Combustíveis, Biocombustíveis, Petróleo e Derivados) pelas análises em Cromatografia gasosa realizadas.

\section{BIBLIOGRAFIA}

[1] BRITO, M., MARTINS, F. "Life cicle assessment of butanol production", Fuel, v.208, pp.476-482, 2017.

[2] XUE, C. et al. "Recent advances and state-of-the-art strategies in strain and process engineering for biobutanol production by Clostridium acetobutylicum”, Biotechnology Advances, v.35, pp.310-322, 2017. 
[3] MISHRA, P. et al. "Outlook of fermentative hydrogen production techniques: An overview of dark, photo and integrated dark-photo fermentative approach to biomass", Energy Strategy Reviews, v.24, p.27-37, 2019.

[4] SATARI, B., KARIMI, K. "Citrus processing wastes: Environmental impacts, recent advances, and future perspectives in total valorization”, Resources, Conservation and Recycling, v. 129, pp. 153-167, 2018.

[5]CITRUSBR- Associação Nacional dos Exportadores de Sucos Cítricos. Press Releases. Estoques: Comunicado ao mercado. Processamento de laranja e produção de suco estimados na safra 2020/21 Disponível em:<http://www.citrusbr.com/pressreleases/> Acesso em: Setembro, 2020.

[6] ABBASI, T., ABBASI, S. A."Renewable Hydrogen: prospects and challenges", Renewable Sustainable Energy Reviews, v.15, pp. 3034-3040, 2011.

[7] DUBOIS, M. et al. "Colorimetric method for determination of sugars and related substances", Analytical chemistry, v. 28, n. 3, pp. 350-356, 1956.

[8] APHA, A. W. Standard methods for the examination of water and wastewater. 20th ed. Washington, D.C.: American Public Health Association, 2005.

[9] AQUINO, S. F., et al. "Metodologias para determinação da atividade metanogênica específica (ame) em lodos anaeróbios", Engenharia sanitaria ambiental, v. 12, n. 2, pp. 192-201, 2007.

[10] MAINTINGUER, S.I., et al. "Fermentative Hydrogen Production of Microbial Consortium", Internacional Journal of Hydrogen Energy, v. 33, p. 4309-4317, 2008.

[11] ADORNO, M.A.T., HIRASAWA, J.S.; VARESCHE, M.B.A. "Developmet and Validation of Two Methods to Quantify Volatile Acids (C2-C6) by GC/FID: Headspace (automatic and manual) and LiquidLiquid Extraction (LLE)", American Journal of Analytical Chemistry, v. 05, pp. 406-414, 2014.

[12] LAY, J.Y.; LI, Y.Y.; NOIKE, T. "Developments of bacterial population and methanogenic activity in a laboratory-scale landfill bioreactor", Water Research, v.32, pp.3673-3679, 1998.

[13] SONG, Z.X., et al. "Effects of pretreatment method of natural bacteria source on microbial community and biohydrogen production by dark fermentation", International journal of hydrogen energy, v. 37, n. 7, p. 5631-5636, 2012

[14] HOELZLE, R.D., VIRDIS, B., BATSTONE, D.J. "Regulation mechanisms in mixed and pure culture microbial fermentation", Biotechnology Bioengineering, v.111,pp. 2139-2154, 2014.

[15] ATASOY, M., EYICE, O., SCHNURER, A., et al. "Volatile fatty acids production via mixed culture fermentation: Revealing the link between $\mathrm{pH}$, inoculum type and bacterial composition" Bioresource Technology, v. 292, 2019.

[16] ZHOUET, M., et al. "Enhanced volatile fatty acids production from anaerobic fermentation of food waste: A mini-review focusing on acidogenic metabolic pathways",Bioresource Technology, v. 248 pp. 6878, 2018.

[17] AL-SHORGANI, et al., "Impact of ph and butyric acid on butanol production during batch fermentation using a new local isolate of clostridium acetobutylicumym1", Saudi journal of biological sciences. v. 25, pp. 339-348, 2018.

[18] NANDA, et al. "Fermentative production of butanol: Perspectives on synthetic biology", New Biotechnology, v. 37, pp.210-221, 2017.

[19] SHINTO, H., et al. "Kinetic study of substrate dependency for higher butanol production in acetonebutanol-ethanol fermentation", Process Biochemistry, v.43, pp.1452-1461, 2008.

[20] PACHIEGA, R., et al. "Hydrogen bioproduction with anaerobic bacteria consortium from brewery wastewater", International Journal of Hydrogen Energy, v.42, pp152-160, 2017.

[21] SOARES, L.A., et al. "Metagenomic analysis and optimization of hydrogen production from sugarcane bagasse", Biomass and Bioenergy, v. 117, pp. 78-85, 2018.

[22] LIU, J., et al. "Study of the co-production of butanol and hydrogen by immobilizing Clostridium acetobutylicum CICC8012”, Energy Procedia, v. 158, pp.1879-1884, 2019.

[23] ETCHEBEHERE, C., et al. "Microbial communities from 20 different hydrogen-producing reactors studied by 454 pyrosequencing", Applied microbiology and biotechnology, v. 100, n. 7, pp. 3371-3384, 2016.

[24] VALDEZ-VAZQUEZ, I., POGGI-VARALDO, H.M. "Hydrogen Production by Fermentative consortia", Renewable and Sustainable Energy Reviews, v.13, pp.1000-1013, 2009.

[25] ALY, S.S., et al. "Identification of factors that accelerate hydrogen production by Clostridium butyricum RAK25832 using casamino acids as a nitrogen source", International Journal of Hydrogen Energy, v. 43, pp. 5300-5313, 2018.

[26] AN, Q., et al. "Investigation on hydrogen production from paper sludge without inoculation and its enhancement by Clostridium thermocellum”, Bioresouce Technology, v. 263, pp.120-127, 2018. 
[27] HAMILTON, C., et al. "Effect of the nitrogen source on the hydrogen production metabolism and hydrogenases of Clostridium butyricum CWBI1009”, International Journal of Hydrogen Energy, v. 43, pp.5451-5462, 2018.

[28] YIN, Y., WANG, J. "Isolation and characterization of a novel strain Clostridium butyricum INET1 for fermentative hydrogen production”, International Journal of Hydrogen Energy, v.42, pp. 12173-12180, 2017.

[29] ROSA, P.R.F. et al. "Hydrogen production from cheese whey with etanol-type fermentation: effect of hydrogen retention time on the microbial community composition", Bioresource Technology. v. 161, 2014.

[30] CASTELLÓ, E. et al. "Stability problems in the hydrogen production by dark fermentation: Possible causes and solutions", Renewable and Sustainable Energy Reviews. v. 119, 2020.

[31] LI, C., FANG, H.H.P. "Fermentative Hydrogen Production From Wastewater and Solid Wastes by Mixed Cultures”, Critical Reviews in Environmental Science and Technology, v.37, pp.1-39, 2007.

[32] MAINTINGUER, S.I., et al. "Hydrogen bioproduction with Enterobacter sp. Isolated from brewery wastewater", International Journal of Hydrogen Energy. v.42, pp. 152-160, 2017.

\section{ORCID}

Daiana Camila da Silva

https://orcid.org/0000-0002-6000-6872

Luan Vieira Adames

https://orcid.org/0000-0002-3912-687X

Lorena Oliveira Pires

https://orcid.org/0000-0002-1447-259X

Rodrigo Fernando Costa Marques

https://orcid.org/0000-0003-0195-3885

Maria Angela Tallarico Adorno

https://orcid.org/0000-0002-5340-889X

Sandra Imaculada Maintinguer

https://orcid.org/0000-0002-4584-7649 